\title{
Nanostructure Findings by Use of a Modified Preparation Method of TEM Samples Collected from the Topmost Surface Layer of Carburized Inconel-718 Superalloy
}

\author{
Corneliu Sârbu
}

Independent researcher. Work done at National Institute for Materials Physics, Măgurele, Romania

The low-temperature (LT) gas atmosphere carburization processing, invented by Swagelok Co. for the surface hardness improvement of 316L austenitic stainless steel (SS), was applied to other SSs, corrosion resistant steels and superalloys [1] including Inconel-718 (IN-718) [2]. The model of colossal supersaturation with interstitial carbon atoms [3,4] of the surface grains crystal lattice, currently accepted as explanation of the SSs surface carburization effects, was automatically extended to the LT surface carburized IN-718 - the subject of this report. The predicted dilatation of matrix lattice that would normally happen in LT carburized IN-718, is denied by the anomaly [2] reported for the IN-718 carburized at $843 \mathrm{~K}$, i.e. an apparent contraction instead of dilatation of the crystalline lattice, occurring inside the topmost layer $\approx 2 \mu \mathrm{m}$ thick. What motivated our study was this anomaly, together with the huge modification of peaks shapes in the X-ray diffractograms (XRD) observed when we scanned the carburized alloy surface. We intended to check the model validity of the colossal lattice supersaturation with $\mathrm{C}$ atoms of the grains from inside the carburized case, tens of $\mu \mathrm{m}-\mathrm{s}$ thick and the grains microstructure, in order to understand the anomaly by use of the JEM-ARM200F microscope.

The ion milling procedure of thinning was adapted with the aim of accessing the microstructure of the topmost layer, a few $\mu \mathrm{m}-\mathrm{s}$ thick, of the carburized at $843 \mathrm{~K}$ free surface of IN-718. This layer contains a highly stressed and fragile material. The adaptation consisted in: (a) a two stage thinning operation, with TEM examination at the end of each stage, the $2^{\text {nd }}$ stage ion milling being applied to the already perforated samples after the $1^{\text {st }}$ stage milling; (b) the dimpling and ion milling of only the uncarburized side of the TEM disk at the $1^{\text {st }}$ stage and the further ion milling of both sides of the already thinned area at the $2^{\text {nd }}$ thinning stage; (c) the use of $\mathrm{Cu}$ contamination of the carburized side during the 1st stage ion milling as a protection and marker of the free carburized surface. The procedure offers the certitude of accessing the microstructure (nanostructure in our case) of the topmost layer, roughly $\approx 5 \mu \mathrm{m}$ thick. We also used a method of rough estimation of depth of the TEM observed nanostructure features.

The nanostructure features identified in the topmost layer about $5 \mu \mathrm{m}$ thick do not resemble the grains microstructure predicted by the carbon supersaturation model. Our findings are the following:

(a) the fragmentation into nanocrystals of the initial matrix rough grains, together with the formation of an amorphous phase that contains either much carbon or no carbon at all, but always contains oxygen and the main alloy elements. We identified low amounts of carbide nanocrystals of type $\mathrm{Cr}_{23-\mathrm{x}} \mathrm{Fe}_{\mathrm{x}} \mathrm{C}_{6}$, $\mathrm{M}_{23} \mathrm{C}_{6}$ and $\mathrm{MC}$, with FCC structure and lattice parameters of $10.62 \AA-11.12 \AA$ and $4.48 \AA$. (Figure-1)

(b) the segregation of Ni nanoclusters at large areas (Figure-2) and at triple junctions (TJ) (Figure-3)

(c) the accumulation of carbon at grain boundaries (GBs) producing cracks (Figure-4)

(d) the agglomeration of the main alloy elements inside the grains, next to GBs and at GBs (Figure-5)

The LT carburization treatment triggers a more complex transformation than the bare carbon paraequilibrium diffusion through the matrix interstitial lattice sites up to the colossal carbon supersaturation. Given the estimated maximum depth of $\approx 9.7 \mu \mathrm{m}$ below the carburized surface which contributed to our XRD-s (reported in literature for IN-718) it is reasonable to suppose that the huge modification of the XRD peaks observed at scanning of the carburized alloy surface indicates a much deeper than $\approx 5 \mu \mathrm{m}$ (see images) depth extension of the case volume where grains fragmentation occurs. The phase instability of IN-718 alloy at $843 \mathrm{~K}$ in gas carburization atmosphere was obvious [5]. 


\section{References:}

[1] S.Collins and P.Williams, Advanced Materials \& Processes (September 2006), p.32;

[2] R.Sharghi-Moshtaghin et al, Metall Mater Trans A, 41A (2010), p.2022

[3] P.C.Williams and S.R.Collins, JOM, 60(12) (2008), p.27

[4] G.M.Michal, F.Ernst and A.H.Heuer, Metall Mater Trans A, 37A (2006), p.1819

[5] The carburization of IN-718 was done at Swagelok facility. The author is grateful to Swagelok Co. Ltd., Solon, OH and to Dept. of Mater. Sci. \& Eng. of Case-Western Reserve Univ., Cleveland, OH for the permission to join the research on surface carburization of IN-718. The financial support of the Romanian Authority ANCSI (Bucharest) for the HR(S)TEM study reported here is acknowledged.

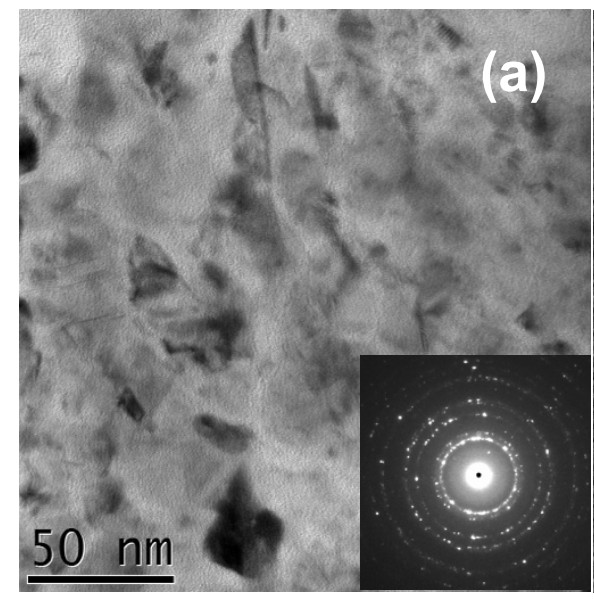

Figure-1. (depth $\approx \mathbf{1 . 5} \boldsymbol{\mu m})$. (a) Bright field TEM image showing the fragmentation of austenitic matrix grains and the presence of a few carbide nanocrystals, identified by several fine spots close to the selected area ED central beam. (b) HRTEM image acquired from the same area as (a), revealing the amorphous phase.

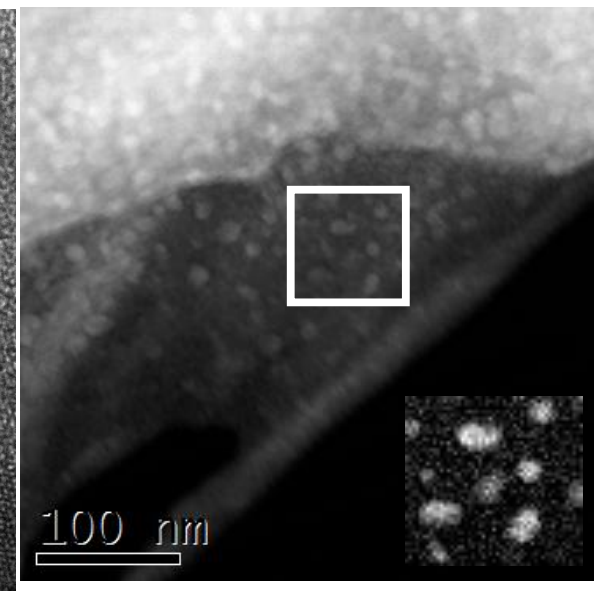

Figure-2 $(\approx 3.5 \mu \mathrm{m})$ Z-contrast of an area with $\mathrm{Ni}$ clusters. Framed area and insert: $\mathrm{Ni}$ identified by means of EELS spectrum imaging.

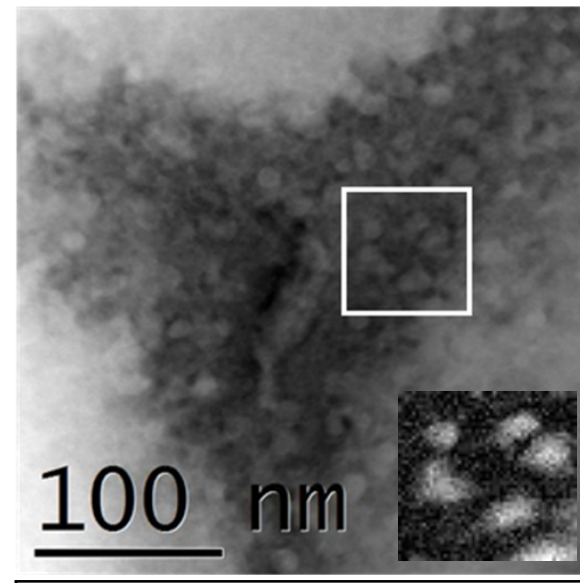

Figure-3 $(\approx 3.5 \mu \mathrm{m})$ clustering of $\mathrm{Ni}$ at a $\mathrm{TJ}$

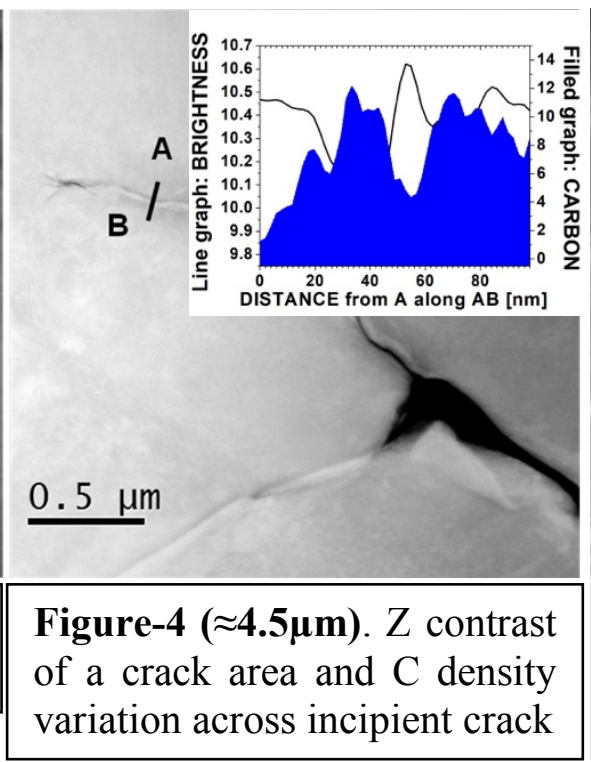

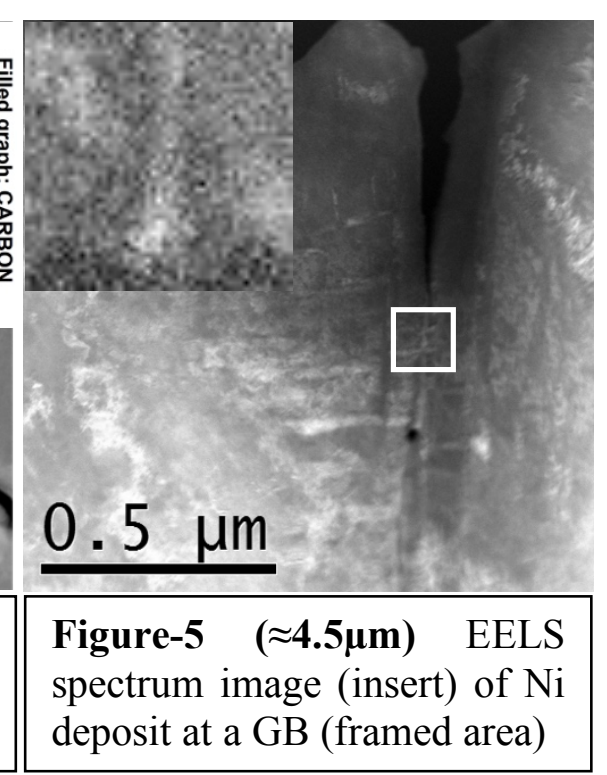

